The champions took an imaginative and creative approach to introducing this change by incorporating role play and case scenarios in their teaching plans.

\begin{tabular}{lllll}
\hline & $\begin{array}{l}\text { April 2009 } \\
\text { to } \\
\text { March 2010 } \\
\begin{array}{l}\text { Prior to } \\
\text { initiative }\end{array}\end{array}$ & $\begin{array}{l}\text { April 2010 } \\
\text { to } \\
\text { March 2011 }\end{array}$ & $\begin{array}{l}\text { April 2011 } \\
\text { to } \\
\text { March 2012 } \\
\text { (high number } \\
\text { of repeated } \\
\text { fallers Jan/Feb) }\end{array}$ & $\begin{array}{l}\text { April 2012 } \\
\text { to } \\
\text { March 2013 }\end{array}$ \\
\hline $\begin{array}{l}\text { Falls not resulting } \\
\text { in injury }\end{array}$ & 45 & 19 & 43 & 28 \\
\begin{tabular}{l} 
Falls resulting in injury \\
\hline
\end{tabular} & 23 & 18 & 14 & 9 \\
\hline
\end{tabular}

The equipment costs of approximately $£ 8,000$ for bed and chair sensors, low beds and crash mats seem a very appropriate investment when considering the results of this initiative, shown in the table above, fall numbers fluctuate but are always lower than prior to the initiative and there is an impressive year on year reduction in the number of injuries sustained. The improvements not only contribute to the organisation's strategic objectives to improve care and safety but assist in providing essential evidence to the Care Quality Commission too.

\section{P136 JOURNEY FOR MEN - A SUPPORT GROUP}

Kevin Benson. Dorothy Gillespie. Donna Louise Children's Hospice, Stoke on Trent, UK

\subsection{6/bmjspcare-2013-000591.158}

The Journey for Men group was started to provide a safe place for men to explore their feelings.

The group consists of men who have either lost a child or are facing the loss of their child.

Aims

- To provide a safe environment for men to openly discuss their feelings about their experiences of having a child with shortened life expectancy or losing a child.

- To encourage open discussion on life issues, family dynamics, coping strategies

- To encourage male friendships, social networking and an opportunity to feel a part of an informal support group.

Approach Used A person centred counsellor facilitates the group providing monthly sessions in the evening at an agreed time.

Sessions are no more than two hours, unless a planned activity occurs. The sessions have no fixed agenda. Chip butties are provided as the men often arrive after work.

Attendance is open ended which encourages growth but also allows men to move on.

Once a quarter an activity is provided away from the hospice to encourage relationship building and social networking.

To date the men have discussed very challenging issues such as:

- Support, caring and friendship among men.

- Facing and working on restrictive and destructive aspects of the male gender role

- Opportunity to discuss supportive roles usually filled by women in the home and in professional settings.

- Attention to unfinished business with our fathers and contemplation of the ways we have related to significant men in our lives.
Outcomes The group is 2 years old and over 30 men have accessed this service and have reported the following changes as a result of attending the group:

- Increased coping mechanisms

- Increased ability to talk about their feelings with their partner

- Greater ease in discussing difficult issues

- Greater ease in exposing vulnerability.

Application to Hospice Practice This is a tried and tested model in engaging a hard to reach group, lessons learnt from this experience are transferable to other hospices.

\section{P137 A WHOLE SCHOOL APPROACH TO LOSS, GRIEF AND BEREAVEMENTS}

${ }^{1}$ Jane Miller, ${ }^{2}$ Jacquie Lindsay, ${ }^{3}$ Jane Kelly, ${ }^{3}$ Michelle Guthie, ${ }^{3}$ Emily McCurrie. ${ }^{1}$ Prince and Princess of Wales Hospice, Glasgow, Scotland, ${ }^{2}$ St. Margarets Hospice, ${ }^{3}$ NHS GGC Health Improvement

\subsection{6/bmjspcare-2013-000591.159}

Many children and young people will experience bereavement, through the loss of a parent, sibling, grandparent, friend or pet. The term 'bereavement' refers to the process of grieving and mourning, and is associated with a deep sense of loss and sadness. It is a natural process; however its effects can be overwhelming.

During bereavement, children and young people can experience a great number of emotions, including sadness, anger, anxiety, guilt, fear, denial, disbelief and confusion. With the right help and support, most children and young people will not require professional help. According to the Child Bereavement Charity, what they do need is people who care and the understanding of familiar and trusted adults. Schools are well placed to provide such support.

A working group has been established with representation from GCC Education Services, Educational Psychology, NHS GG\&C Health Improvement and Glasgow Hospice staff. The purpose of the group is to promote a planned and progressive approach to teacher training around supporting children and young people experiencing bereavement, loss and change in line with a Curriculum for Excellence, across educational settings to ensure consistency in relation to Bereavement \& Loss. To support and equip staff to take forward learning around bereavement, loss and change with access to high quality resources and training. and to develop an online resource that can be updated as new information becomes available.

To date two study days have been facilitated each with 30 delegates from a range of early years, primary secondary and special needs schools. The evaluations were extremely positive. Future study days are in the planning process with the aim that these days will be ran twice yearly for the foreseeable future. The online resource is complete with a launch date planned for Summer 2013.

\section{P138 COOKING WITH CHRIS: THE TEENAGER PROGRAMME}

Tania Brocklehurst, Gill Sears, Chris To. Hospice of St Francis, Berkahamsted, UK

\subsection{6/bmjspcare-2013-000591.160}

Strobe and Schut's (1999), Dual Process Model suggests that a healthy grieving process involves oscillating between life restoration and grief orientation activities. Following the success of 
the Hospice of St Francis, 2012 bereaved adults "Cooking with Chris" programme, we developed a 5 -week teenagers course. This is a difficult age group to connect with. Food was used as a therapeutic bridge. Vital cooking skills were learnt and the experience and feelings of loss and grief addressed.

Bereaved teenagers between 11 and 18 years from the Hospice fortnightly 'drop in' took part. They had experienced the death of a close family member. Ideally, they attended with a significant adult.

After introductions and a practical induction to the hospice kitchen, weekly themed menus such as 'Amazing Mince' and 'Sausage Surprise' were produced. Undertaking the course was not without its challenges. There were no existing guidelines. One aspect was the emotional impact on the facilitators. A robust debriefing process was crucial for promoting understanding and resilience in the course staff and volunteers. Further anxiety was overcome about teens messing around if bored and how to control such behaviour in a busy working kitchen, whereas the previous adult groups have been very noisy, the teens were relatively quiet, probably as they were so busy concentrating!

Highlights included seeing the teens coming out of their shells and observing the parents working with the children. Parents found support in each other. Feedback commented how important it had been for their teen to come back to the hospice to do something enjoyable, adding positive memories to the sad ones she held of her Father dying there.

We believe that this programme provides innovative bereavement support for teenagers in a therapeutic, meaningful and fun way. Guidelines for others doing similar have been produced.

\section{P139 BUILDING CAPACITY AND COMPASSION: PILOTING A COLLABORATIVE PROJECT TO ENABLE YOUNG PEOPLE TO SUPPORT OTHERS WHO EXPERIENCE DEATH, BEREAVEMENT AND LOSS}

Nikki Archer, Pat Owen, Jane Beckett. St Giles Hospice, Lichfield, england

\subsection{6/bmjspcare-2013-000591.161}

St Giles Hospice has worked in collaboration with a local secondary school to pilot a 1 hour workshop for Year 8 pupils as part of their PSE programme. The work shop was accredited by Education Transformation, Staffordshire Education Authority and was facilitated by trained volunteers. Students were invited to create a young person through whom they were able to explore issues relating to death, bereavement and loss. Over 200pupils participated.

Peer support is a key aspect of the support young people identify as being helpful in enabling them to adapt and cope with bereavement. Building capacity and compassion within our community is a key strategic aim.

Evaluation A number of key themes were identified from the students feedback. The students felt it enabled them to:

- listen to each other

- understand others feelings

- respecting difference

- talk safely about death, bereavement and loss.

- understand the impact on the listener

Only 5 students stated they felt they had gained nothing from the session

The facilitators feedback indicated that generally students were:
- engaged and eager to share their ideas and experiences.

- enabled to understand issues relating to death, bereavement and loss.

- enabled to identify how they might support a friend who had suffered a loss

The role of the teacher and the need for the practicalities to have been agreed was highlighted.

Teachers feedback indicated that the workshop was well delivered, helpful and informative giving an opportunity for young people to understand the issues.

The project forms part of the Hospice's programme for building compassion and capacity within our local community. Additional opportunities for fundraising and volunteering were identified. We plan to build on the success of the project by exploring opportunities to work in partnership with other local organisations to deliver the workshops.

\section{P140 KYLIE, JASON, CHANTELLE AND JESS: CREATING CHARACTERS AS A CATALYST FOR CHANGE. ENABLING THE COMMUNITY TO UNDERSTAND AND MEET THE NEEDS OF YOUNG PEOPLE EXPERIENCING LOSS AND BEREAVEMENT}

${ }^{1}$ Nikki Archer, ${ }^{2} J e n n i$ Coleman, 'Carol Rodgers, ${ }^{1}$ Helen Chetwynd. 'St Giles Hospice, Lichfield, England, '2 Lichfield Disrict Safer Community Partnership

10.1136/bmjspcare-2013-000591.162

A collaborative project between St Giles Hospice and Lichfield District Safer Community Partnership was undertaken which aimed to

- build sustained confidence and capacity of community staff to enable them to help and support young people who are coping with loss and bereavement.

- For children and young people within our local community to be better supported and understood through their loss experiences

There is strong evidence that bereavement and the changes that accompany it can make children and young people vulnerable to poor outcomes, particularly in disadvantaged circumstances. Many children and young people are able to accommodate and adjust to their loss if they receive the right help and support through their usual networks, however, those who work with young people tell us they feel ill equipped to support young people who have experienced loss and bereavement.

During a half day workshop participants were afforded an opportunity to explore death, dying, bereavement and loss through the creation of a character based within their own experiences.

Pre and post workshop participants were asked to rate how confident they felt

- talking to young people about death and dying?

- supporting a young person who has been bereaved?

The results were very positive.

- 58 attended

- $94 \%$ assessed themselves with a higher post workshop score, the average score increased from 5 to 8 for both questions. All valuedthe workshop.

- A follow up focus group was held 9 months after the initial workshop. Feedback demonstrated the ripple effect the workshop had ona personal and professional 